\title{
Aislamiento e identificación de pestivirus obtenidos de alpacas (Lama pacos) y llamas (Lama glama) de la Región Metropolitana, Chile ${ }^{\#}$
}

\author{
Isolation and identification of pestiviruses in alpacas (Lama pacos) and llamas (Lama glama) \\ introduced to the Región Metropolitana, Chile \\ M O Celedón*, J Osorio, J Pizarro \\ Universidad de Chile, Facultad de Ciencias Veterinarias y Pecuarias, Santiago, Chile.
}

\begin{abstract}
SUMMARY
The natural habitat for more than $90 \%$ of the domestic South American camelids (SAC) in Chile, alpaca (Lama pacos) and llama (Lama glama), is located between $11^{\circ}$ and $21^{\circ}$ South latitude at 3,800 and 5,000 ms of altitude. Lately, alpacas and llamas have been introduced to other geographic parts of the country where they are in contact with domestic ruminants, making likely infection with BVDV, present in cattle, goats and sheep. The BVDV includes two species, BVDV genotype I (BVDV I) and BVDV genotype II (BVDV II), which along with the border disease virus (BDV) and classical swine fever virus (CSFV) conforms the Pestivirus genus of the Flaviviridae family. This study evaluates the hypothesis that SAC introduced to the Metropolitan Region (MR) of Chile are infected with pestiviruses. In order to perform viral isolation, samples were taken from $80 \mathrm{SAC}(42$ live alpacas, 35 live llamas, 2 dead llamas and 1 aborted foetus of llama), coming from 4 flocks suspected to be infected with pestivirus. The samples were inoculated in primary culture of bovine foetus lung cells (free of BVDV), passing each sample 5 times, and were then analyzed by direct immunofluorescence and indirect immunoperoxidase techniques to detect the presence of pestivirus antigens. For molecular characterization, a fragment of the 5'-untranslated region (5'-UTR) of RNA of the isolates was amplified by reverse transcription-polymerase chain reaction (RT-PCR) and treated with restriction enzymes Pst I, Bgl I and Xho I in order to identify species of viruses. The results show that 18 SAC (10 alpacas and 8 llamas from the 4 studied flocks), were infected with pestivirus. All isolates were non cytopathogenic. BVDV I was isolated from 6 alpacas while BVDV II was isolated from 4 alpacas and 8 llamas. The viral samples were obtained from 8 healthy alpacas, 2 alpacas with abortion, 5 healthy llamas, 2 llamas with abortion and 1 dead llama without clinical history. It is concluded that alpacas and llamas from the MR of Chile are infected with BVDV I and BVDV II.
\end{abstract}

Palabras clave: Camélidos, sudamericanos, DVB, pestivirus.

Key words: South American camelids, pestiviruses, bovine viral diarrhoea virus.

\section{INTRODUCCION}

El género Pestivirus, perteneciente a la familia Flaviviridae, incluye al virus de la diarrea viral bovina (VDVB), al virus de la enfermedad de la frontera (VEF) y al virus de la peste porcina clásica (VPPC). El VDVB infecta rumiantes domésticos, rumiantes silvestres y cerdos; el VEF infecta ovinos, caprinos y cerdos. El VPPC infecta cerdos (Vilcek y Belak 1996, Walz y col 1999).

El VDVB, VEF y VPPC poseen antígenos comunes y propios, pero sólo se define un serotipo por especie viral, pese a que los aislados virales presentan una alta diversidad antigénica (Corapi y col 1990, Xue y col 1990, Paton y col 1991, Paton y col 1995a, Ridpath y col 2000). De acuerdo a la capacidad que tiene el virus para provocar efectos visibles en cultivos de células in vitro, se des-

Aceptado: 02.08.2005.

\# FONDECYT 1981193.

* Fax 5416840

correo electrónico oceledon@uchile.cl casilla 2, correo 15, Santiago, Chile. criben dos biotipos, citopático y no citopático (Lee y Gillespie 1957). El análisis de diferentes regiones del genoma y en particular de la región $5^{\prime}$ no traducida (5'UTR) ha permitido clasificar los Pestivirus en 4 grupos: VDVB genotipo I (VDVB I), VDVB genotipo II (VDVB II), VEF y VPPC (Pellerin y col 1994, Ridpath y col 1994, Vilcek y col 1994). Actualmente se han obtenido nuevos aislados virales a partir de animales silvestres y el análisis de su genoma ha llevado a postular su inclusión como nuevas especies de pestivirus (Becher y col 1997, Becher y col 1999, Harasawa y col 2000).

El VDVB se distribuye en la población bovina mundial y produce, principalmente, infecciones que afectan los aparatos digestivo y respiratorio (Baker 1987). La infección de hembras en gestación puede producir aborto, muerte perinatal, o el nacimiento de terneros persistentemente infectados (Brownlie 1990). En el año 1994, en Estados Unidos de Norteamérica y en Canadá surgió una enfermedad severa con mortalidad mayor a un $25 \%$ que se denominó "síndrome hemorrágico" o "diarrea viral bovina aguda severa". En todos los casos se aisló VDVB II (Pellerin y col 1994, Ridpath y col 1994). El VDVB II también se ha aislado de bovinos con 
enfermedad clínica moderada o desde animales sin síntomas de enfermedad (Ridpath 2003).

En ovinos la infección con el VDVB I o con el VDVB II produce signos clínicos similares a los producidos por el VEF (Giangaspero y Harasawa 2004). En otras especies, como cabras, rumiantes exóticos y camélidos del viejo y nuevo mundo, los signos clínicos producidos por el VDVB son similares a los descritos para el bovino, pero la presentación de la enfermedad es de menor frecuencia (Loken 1995).

En Chile el VDVB está ampliamente difundido en el ganado bovino (Reinhardt y col 1990, Celedón y col 1996, Celedón y col $1997^{\mathrm{a}}$ ) identificándose la presencia de los genotipos VDVB I y VDVB II (Aguilera 2001, De Calisto 2001) en el ganado nacional, aunque no se han descrito casos de enfermedad grave. También se ha detectado el VDVB I en ovinos y caprinos (Müller 2003) y anticuerpos neutralizantes para el VDVB en alpacas (Lama pacos) y llamas (Lama glama) ubicadas en la Región Metropolitana (RM) y en contacto con ganado doméstico. Sin embargo, no se han pesquisado animales con anticuerpos para el VDVB en guanacos (Lama guanicoe) de la Región de Aysén y Magallanes ni en vicuñas (Vicugna vicugna) de la Región de Tarapacá (Celedón y col 2001).

Debido a que algunos productos obtenidos de los camélidos sudamericanos (CSA), como la fibra, la carne y el cuero, muestran interesantes perspectivas de mercado, en los últimos años se ha tratado de impulsar el desarrollo de esta ganadería, lo que ha llevado a un aumento en la frecuencia de transporte de animales desde el altiplano chileno a diferentes regiones del país. El cambio de ambiente y la posibilidad de contacto con el ganado doméstico facilita la posibilidad de que los CSA se infecten con el VDVB pudiendo hacer cuadros clínicos de variada gravedad y/o servir de reservorio para las especies susceptibles. A base de lo anterior, el objetivo de este trabajo fue aislar e identificar pestivirus desde alpacas y llamas introducidas en la R.M.

\section{MATERIAL Y METODOS}

Muestras. De 42 alpacas y 35 llamas vivas se tomaron muestras de sangre, una llama murió al día siguiente de haberse tomado la muestra. De 2 llamas adultas muertas y de 1 feto de llama abortado se tomaron muestras de tejidos (bazo, ganglios linfáticos, hígado, pulmón o riñón). Todas las muestras provenían de animales entre 4 y 10 años, ubicados en 4 rebaños (A, B, C y D) de 4 comunas diferentes de la R.M. Para el rebaño A se contaba con el antecedente de la existencia de una alpaca y una oveja con anticuerpos para pestivirus y que las alpacas estaban separadas de corrales de bovinos, ovinos y caprinos por no más de tres metros; todos los animales del predio presentaban apariencia de estar sanos. El rebaño B estaba constituido por 200 alpacas, llamas y algunas ovejas; se tenía el antecedente que en un período de 9 meses había ocurrido un episodio de enfermedad respiratoria, digestiva y abortos. De 41 hembras preñadas 26 abortaron muriendo 8 y, además, murió una hembra que parió un mortinato (Miranda 2000); por análisis serológico, de 32 hembras sobrevivientes, en 7 se detectaron anticuerpos para pestivirus (Celedón y col 2001). El rebaño C constituido por 45 llamas; en un período de 4 meses las llamas sufrieron fiebre, 6 abortaron y 5 de ellas murieron, a la necropsia los intestinos se observaron enrojecidos. No se detectaron animales serorreaccionantes a pestivirus. En el rebaño D, 3 de 11 llamas presentaban anticuerpos para pestivirus (Celedón y col 2001); 2 se encontraron muertas, sin antecedentes previos de estar enfermas.

De la muestra de sangre sin coagular se extrajeron plasma y leucocitos, mediante un gradiente de densidad de Ficoll Hipaque ${ }^{\circledR}$ (densidad 1,077). De la sangre coagulada se extrajo suero. Los fragmentos de tejidos fueron procesados separadamente para la obtención de inóculos. El plasma, los leucocitos, el suero y los inóculos se conservaron a $-40^{\circ} \mathrm{C}$ hasta ser sometidos al aislamiento viral.

Aislamiento viral. Las células y el suero equino, previos a ser usados en el aislamiento viral, fueron verificados de estar libres de infección con el VDVB, por prueba de inmunofluorescencia directa (IFD) que emplea un conjugado fluorescente policlonal para el VDVB*, y por prueba de inmunoperoxidasa indirecta (IPI) que emplea un "kit" comercial que contiene una mezcla de 4 anticuerpos monoclonales para el VDVB\#. En el aislamiento viral se empleó el procedimiento recomendado por la OIE (2000), con algunas modificaciones. Las muestras se inocularon en volumen de 200 ul sobre monocapas de cultivos primarios constituidos por, aproximadamente, 400.000 células de pulmón fetal bovino, en su quinto pasaje, con 24 horas de crecimiento en $\mathrm{MEM}^{\circ}$ adicionado de un $10 \%$ de suero equino ${ }^{\star}$. Luego de incubar por 60 minutos a $37^{\circ} \mathrm{C}$ se agregó MEM con un $2 \%$ de suero equino. Las células inoculadas y sin inocular (a modo de control celular) se incubaron a $37^{\circ} \mathrm{C}$ por un período de 5 días efectuándose observaciones microscópicas diarias para controlar viabilidad celular, toxicidad de las muestras, efecto citopático y contaminación bacteriana o fúngica. Al quinto día se lisaron mediante 3 ciclos de congelación y descongelación. Los cultivos celulares inoculados con las muestras de suero, plasma y/o linfocitos procedentes de un mismo animal, después del primer pasaje se reunieron en una alícuota para volver a inocularse sobre una nueva monocapa celular; las cosechas

\footnotetext{
Central Veterinary Laboratory, Weybridge, Cat. N PA 0205-08.

\# Central Veterinary Laboratory, Weybridge, Cat. No PA 0258.

- Medio Esencial Mínimo Eagle, GIBCO BRL Cat. No 41500-067.

- HyClone Cat. No SH 3007403.
} 
constituidas por muestras de tejidos se continuaron inoculando en forma separada. El proceso se repitió 5 veces.

Identificación antigénica de los aislados virales. Para pesquisar la presencia de antígenos de pestivirus se aplicaron las pruebas, antes descritas, de IFD en células crecidas en laminillas dispuestas en tubo y de IPI en células crecidas en microplacas.

Identificación genómica de los pestivirus aislados. Los aislados virales obtenidos a partir de los camélidos, e identificados como pestivirus por las pruebas de IFD e IPI, se identificaron genómicamente por RT-PCR y posterior análisis con enzimas de restricción. Para ello se extrajo el ARN total de monocapas de células infectadas con el virus, utilizando Trizol LS, según instrucciones del proveedor (Invitrogen, USA). El ARN obtenido se resuspendió en agua destilada libre de ADNasas y ARNasas y se guardó a $-20^{\circ} \mathrm{C}$ hasta el momento de realizar la PCR.

La transcripción inversa del ARN y la posterior amplificación por PCR (RT-PCR) de la región 5' UTR del genoma de los pestivirus se realizó de acuerdo a las condiciones optimizadas en el laboratorio de Virología de la Facultad de Ciencias Veterinarias y Pecuarias de la Universidad de Chile. Los partidores utilizados para la RTPCR fueron 326: 5'-TCAACTCCATGTGCCATGTAC3' y 324: 5'-ATGCCCTTAGTAGGATAGCA-3 con ubicación 395-375 y 108-128 en el genoma de la cepa NADL del VDVB, respectivamente (Vilcek y col 1994).

La transcripción inversa se realizó en un volumen de 10 ul, bajo las siguientes condiciones: Tris $\mathrm{HCl} 20 \mathrm{mM}$; $\mathrm{KCl} 50 \mathrm{mM}$; ditiotreitol $5 \mathrm{mM}$; 10 pmoles de partidor 326; $\mathrm{MgCl}_{2} 8 \mathrm{mM}$; dATP, dCTP, dGTP, dTTP 0,5 mM de cada uno; Thermoscript transcriptasa inversa (GIBCO, USA) 1U; inhibidor de ribonucleasa Rnasa OUT (GIBCO-BRL) 2U. La reacción se realizó por 45 minutos a $55^{\circ} \mathrm{C}$ y luego se incubó 5 minutos a $90^{\circ} \mathrm{C}$ para inactivar la enzima.

La PCR se realizó en un volumen de 25 ul, de acuerdo a las siguientes condiciones: Tris $\mathrm{HCl} 20 \mathrm{mM}, \mathrm{KCl}$ $50 \mathrm{mM} ; \mathrm{MgCl}_{2} 2 \mathrm{mM}$; ditiotreitol $2 \mathrm{mM}$; dATP; dCTP, dGTP, dTTP, 0,2 mM de cada uno; $2 \mathrm{U}$ de inhibidor de ribonucleasa Rnasa OUT (GIBCO-BRL); partidor 324 10 pmoles; Taq polimerasa 2,5U (GIBCO) y $10 \mathrm{ul} \mathrm{de} \mathrm{la}$ reacción de transripción inversa. La PCR se realizó de acuerdo al siguiente programa: desnaturación inicial a $94^{\circ} \mathrm{C}$ por 2 minutos, seguido de 40 ciclos de alineaciónelongación-desnaturación del $\mathrm{ADN}$ a $55^{\circ} \mathrm{C}$ por 30 segundos, $72^{\circ} \mathrm{C}$ por 3 minutos y $94^{\circ} \mathrm{C}$ por 30 segundos. Para el último ciclo el tiempo de extensión fue de 10 minutos. La reacción de amplificación se realizó en un termociclador con placa difusora de calor (PTC -100 . MJ Research Inc).
Como control negativo de la reacción de RT-PCR se utilizó el ARN total extraído a partir de monocapas de células de pulmón fetal bovino no inoculadas con muestras y libres de pestivirus. Como control positivo se utilizó el ARN total extraído de monocapas de células de pulmón fetal bovino, infectadas con la cepa NADL del VDVB.

El fragmento de ADN amplificado se visualizó por electroforesis en gel de poliacrilamida al $7,5 \%$ en tris borato EDTA (TBE) y posterior tinción con nitrato de plata (Espejo y Escanilla 1993). La electroforesis se llevó a cabo a 150 Volt por 1 hora.

$\mathrm{El}$ fragmento amplificado del ADN se determinó por la detección, en el gel, de una banda de 288 pb.

Genotipificación de los aislados de pestivirus. La determinación de los genotipos de los aislados de pestivirus obtenidos a partir de los CSA se realizó a través del análisis de los patrones de fragmentos de ADN, obtenidos luego de cortar el ADN sintetizado por la RT-PCR, con las enzimas de restricción (ER) $B g l$ I, Xho I y Pst I (RFLP) (cuadro 1) (Vilcek y col 1994, Paton y col 1995b, Harpin y col 1995). Para ello, $50 \mathrm{ng}$ del fragmento de ADN amplificado se incubaron con $5 \mathrm{U}$ de cada una de las enzimas de restricción por 3-4 horas a $37^{\circ} \mathrm{C}$. Luego, los fragmentos de ADN se separaron por electroforesis en gel de poliacrilamida al 15\% en TBE (150 volt durante 105 minutos) y se tiñeron con nitrato de plata (Espejo y Escanilla 1993). La identificación de los distintos tipos de pestivirus se realizó según lo mostrado en el cuadro 1 (Vilcek y col 1994, Paton y col $1995^{\text {b }}$, Harpin y col 1995).

\section{RESULTADOS}

En los 4 rebaños de CSA ubicados en la R.M. se detectó presencia de animales infectados con pestivirus. En el rebaño A, se aisló VDVB en la sangre de 5 de las 12 alpacas muestreadas; en el rebaño B, de las muestras de sangre de 32 alpacas, en 5 se aisló pestivirus; en el rebaño $C$ de las muestras de sangre de 22 llamas, en 3 se pesquisó pestivirus, en tanto que desde muestras de bazo, ganglio linfático, hígado, pulmón y riñón obtenidos de una llama adulta muerta y desde muestras de hígado y pulmón obtenidos de un feto abortado, no se aisló pestivirus; en el rebaño $\mathrm{D}$, de las muestras de sangre de 11 llamas, en 4 se pesquisó pestivirus y en una muerta se aisló pestivirus desde las muestras de bazo, ganglio, pulmón y riñón (llama 1.064) (cuadro 2).

A excepción de la alpaca 10 del rebaño A, que entregó un resultado negativo a la prueba de IFD y de la llama 796 del rebaño C, en que no fue posible precisar el diagnóstico por la prueba de IFD, las muestras de los 16 camélidos restantes fueron diagnosticadas como positivas por los dos procedimientos empleados (IFD, IPI), sólo hubo diferencias en la cantidad de células que 
demostraron presencia de antígenos de pestivirus y también en la intensidad de la coloración, con respecto a una misma prueba (cuadro 1)

En ninguno de los cultivos celulares inoculados, luego de 5 pasajes de las muestras, se detectó presencia de efecto citopático en las monocapas celulares, considerándose a todos los aislados de pestivirus como virus no citopáticos.

En todos los virus aislados se pudo amplificar por RT-PCR la región 5' UTR del genoma viral, confirmando su identificación como pestivirus. Ninguno de los fragmentos de ADN obtenidos por la RT-PCR fue digerido simultáneamente por las enzimas de restricción Pst I, Bgl I y Xho I, lo que indica que no habrían aislados del VPPC. Fragmentos de ADN obtenidos por la RT-PCR a partir de 6 aislados de pestivirus obtenidos desde alpacas, fueron digeridos por las enzimas Pst I y Xho I, lo que identificó a estos pestivirus como virus del genotipo I del VDVB (VDVB-I). Por otra parte, fragmentos de ADN obtenidos de 4 alpacas y de 8 llamas fueron digeridos por la enzima 'Xho I y no fueron digeridos por la enzima Pst I, identificándolos como virus del genotipo II del VDVB (VDVB-II) (cuadro 1). No se observaron fragmentos de ADN digeridos únicamente por la enzima Pst I, lo que indica que ninguno de los pestivirus aquí obtenidos corresponde a un VEF.

\section{DISCUSION}

Al aislar e identificar VDVB en CSA naturalmente infectados, se confirma la infección por pestivirus en los CSA de Chile, preliminarmente detectada a través de la identificación de animales con anticuerpos que neutralizan al VDVB (Celedón y col 2001).

El alto porcentaje de aislamientos se atribuye a que se realizó un muestreo dirigido a rebaños de CSA donde se sospechaba de la presencia del virus, dado por la detección de animales serorreaccionantes al VDVB, por antecedentes de la existencia de CSA enfermos con una patología atribuible a pestivirus, y por estar en contacto con ganado bovino, ovino o caprino susceptible de estar infectado con pestivirus. En segundo término, se inoculó, por separado, en diferentes monocapas de células, diferentes inóculos procedentes de un mismo animal, y en tercer lugar se aumentó el número de pasajes de la muestra en los cultivos celulares, de 3 (que es lo recomendado por los estándares) a 5, a base de experiencias previas en el laboratorio, donde se ha observado que muestras que resultan negativas al tercer pasaje se hacen positivas al aumentar el número de pasajes a 5 .

Si bien con este estudio no es posible conocer el origen de la infección en estos CSA, es probable que lo sea por el contacto con bovinos, lo que se sustenta en que no se detectó presencia de anticuerpos para el VDVB en vicuñas de la Región de Tarapacá y en guanacos de la Región de Aysén y Magallanes (Celedón y col 2001),
Cuadro 1. Patrones de digestión de VPPC ${ }^{*}$, VDVB I, VDVB $\mathrm{II}^{\bullet} \mathrm{y} \mathrm{VEF}^{\#}$ con las ER ${ }^{\circ}$ Pst I, Bgl I y Xho I.

Digestion patterns of classical swine fever virus, bovine viral diarrhea virus genotype I, bovine viral diarrhea virus genotype II and border disease virus with the restriction endonucleases Pst I, Bgl I and Xho $I$.

\begin{tabular}{lcccc}
\hline ER & VPPC & VDVB I & VDVB II & VEF \\
\hline F & & & & \\
Pst I & + & + & - & + \\
Bgl I & + & - & - & - \\
Xho I & + & + & + & - \\
\hline
\end{tabular}

+: Digestión del ADN con la enzima

- : Ausencia de digestión con la enzima.

(Vilcek y col 1994, Paton y col $1995^{\text {b }}$, Harpin y col 1995).

* virus peste porcina clásica

- virus diarrea viral bovina genotipo I

- virus diarrea viral bovina genotipo II

\# virus enfermedad de la frontera

enzimas de restricción

Cuadro 2. Genotipos de los aislados del virus diarrea viral bovina obtenidos de alpacas y llamas de la Región Metropolitana.

Genotypes of bovine viral diarrhea virus isolates obtained from alpacas and llamas of the Región Metropolitana.

\begin{tabular}{|c|c|c|c|c|}
\hline Rebaño & Animal & $\operatorname{IFD}^{(a)}$ & $\mathrm{IPI}^{(\mathrm{b})}$ & Genotipo \\
\hline \multirow[t]{5}{*}{ A } & Al 2: 우 & + & + & II \\
\hline & Al 7: $\sigma^{7}$ & ++ & +++ & I \\
\hline & Al 10: $q$ & - & +++ & II \\
\hline & Al 12: $\sigma^{\top}$ & + & ++ & II \\
\hline & $\mathrm{Al}$ 27: 우 & + & ++ & II \\
\hline \multirow[t]{5}{*}{$\mathrm{B}$} & Al 285: $q$ & +++ & +++ & I \\
\hline & Al 286: ${ }^{\circ}(\mathrm{c})$ & +++ & +++ & I \\
\hline & Al 288: $\oint^{\top}(\mathrm{c})$ & + & +++ & I \\
\hline & Al 345: ᄋ & + & +++ & I \\
\hline & Al 350: & + & +++ & I \\
\hline \multirow[t]{3}{*}{$\mathrm{C}$} & Ll 791: ${ }^{(c)}$ & ++ & +++ & II \\
\hline & Ll 794: ${ }^{\prime}(\mathrm{c})$ & +++ & ++ & II \\
\hline & Ll 796: 우 & ND & + & II \\
\hline \multirow[t]{5}{*}{$\mathrm{D}$} & Ll 620: SNI & +++ & + & II \\
\hline & L1 621: SNI & +++ & + & II \\
\hline & Ll 622: SNI & +++ & + & II \\
\hline & Ll 626: SNI & ++ & +++ & II \\
\hline & Ll 1064: SNI & ++ & ++ & II \\
\hline
\end{tabular}

${ }^{(a)}$ Inmunofluorescencia directa; ${ }^{(b)}$ Inmunoperoxidasa indirecta; ${ }^{(c)}$ con aborto; Al alpaca; L1 llama; + hembra; $\sigma^{7}$ macho; + menos del $25 \%$ de las células con reacción; ++ de 25 a $50 \%$ de las células con reacción; +++ sobre el $50 \%$ de las células con reacción; ND no determinado; SNI sexo no identificado.

lugares donde el ganado bovino es escaso o no existe y el ganado ovino se maneja en forma extensiva. Otro antecedente es que los aislados resultaron ser no citopáticos y de genotipo I y II, lo que corresponde a las características de los VDVB obtenidos de bovinos de diferentes regiones del país (Meléndez y Celedón 1995, Celedón y 
col 1997 , Celedón y col 1998, Aguilera 2001, De Calisto 2001) y, en parte, diferente a los pestivirus obtenidos de ovinos y caprinos en que sólo han resultado ser VDVB I, con una proporción similar de aislados citopáticos y no citopáticos (Müller 2003); y, por último, se describe que el ganado bovino es la fuente de infección más probable para los CSA (Wentz y col 2003).

La literatura señala que los pestivirus no serían patógenos importantes para los CSA, dado que la inoculación experimental de llamas, con aislados de VDVB, no produjo enfermedad y la respuesta de anticuerpos seroneutralizantes fue pobre (Wentz y col 2003). Además, los únicos antecedentes clínicos existentes señalan que el VDVB se ha aislado desde llamas con descarga nasal excesiva y con diarrea (Evermann y col 1993, Mattson 1994). Sin embargo, en este estudio, a excepción del rebaño A, que fue el único en que no se registraban antecedentes de enfermedad clínica al momento de tomar las muestras, en los otros tres había fuertes sospechas de la participación de un pestivirus. Se suma a lo anterior el hecho de que nunca se detectó efecto citopático en los cultivos celulares, haciendo poco probable la participación de otros virus en los cuadros clínicos, tales como virus herpes, virus parainfluenza o adenovirus, entre otros, que son virus que producen efecto citopático en los cultivos celulares.

En definitiva, se concluye que las alpacas y llamas introducidas a la R.M. están infectadas con VDVB I y VDVB II, desconociéndose el lugar y fuente de la infección, pero sospechándose del rol de los bovinos en la transmisión del virus. Además, se sospecha fuertemente del VDVB como agente responsable de los graves cuadros clínicos observados en estas especies.

Los resultados obtenidos en este trabajo sugieren a futuro estudiar el impacto de la infección con cepas nacionales de pestivirus en la salud de los CSA y, además, evaluar el probable rol de los CSA como especies reservorio del virus, tanto para rumiantes domésticos como silvestres.

\section{RESUMEN}

El ambiente natural para más del 90\% de las alpacas (Lama pacos) y llamas (Lama glama), camélidos sudamericanos (CSA) domésticos de Chile, se ubica entre $\operatorname{los} 11^{\circ}$ y $21^{\circ}$ latitud sur a 3.800 y $5.000 \mathrm{~m}$ de altitud. En el último tiempo las alpacas y las llamas han sido introducidas en otros lugares geográficos del país, donde toman contacto con rumiantes domésticos, facilitándose la infección con el virus diarrea viral bovina (VDVB) que está presente en bovinos, ovinos y caprinos de Chile. El VDVB incluye a dos especies, VDVB genotipo I y VDVB genotipo II, que junto con el virus de la enfermedad de la frontera (VEF) y el virus de la peste porcina clásica (PPC) conforman el género Pestivirus de la familia Flaviviridae. Este estudio evalúa la hipótesis que los CSA introducidos en la Región Metropolitana (R.M.) de Chile están infectados con pestivirus. Para hacer el aislamiento viral se tomaron muestras de 80 CSA de la RM, 42 alpacas y 35 llamas vivas, 2 llamas muertas y un feto abortado provenientes de 4 rebaños sospechosos de estar infectados con pestivirus. Las muestras fueron inoculadas en cultivos celulares primarios de pulmón fetal bovino (libre de VDVB), subcultivando por 5 veces cada muestra. Para detectar antígenos de pestivirus, las células con las muestras fueron analizadas por prueba de inmunofluorescencia directa y de inmunoperoxidasa indirecta. Para la caracterización molecular, una fracción del fragmento no traducido del genoma viral (5'UTR) de los aislados fue amplificado por RT-PCR y posteriormente, para identificar las especies virales, fue tratado con las enzimas de restricción Bgl I, Pst I y Xho I. Los resultados muestran que 18 CSA, 10 de alpacas y 8 de llamas de los 4 rebaños estudiados estaban infectadas con pestivirus. Todos los aislados fueron no citopáticos. En 6 alpacas se aisló VDVB I y en 4 alpacas y 8 llamas se aisló VDVB II. El virus fue obtenido desde 8 alpacas sanas, 2 alpacas con aborto, 5 llamas sanas, 2 llamas con aborto y una llama muerta sin antecedentes de enfermedad clínica. Se concluye que alpacas y llamas ubicadas en 4 rebaños de la R.M. se encuentran infectados con el VDVB genotipo I y con el VDVB genotipo II.

\section{REFERENCIAS}

Aguilera M. 2001. Caracterización genotípica de aislados nacionales del virus diarrea viral bovina (VDVB) mediante enzimas de restricción. Memoria de titulación, Escuela de Ciencias Veterinarias. Universidad de Chile.

Baker J C. 1987. Bovine viral diarrhea virus: A review. J Am Vet Med Assoc 190, 1449-1457.

Becher P, M Orlich, A D Shannon, G Horner, M Konig, H J Thiel. 1997. Phylogenetic analysis of pestiviruses from domestic and wild ruminants. J Gen Virol 78, 357-1366.

Becher P, M Orlich, A Kosmidou, M König, M Baroth, H J Thiel. 1999. Genetic diversity of pestiviruses: identification of novel groups and implications for classification. Virology 262, 64-71.

Brownlie J. 1990. The pathogenesis of bovine virus diarrhoea virus infections. Rev Sci Technical 9, 43-59.

Celedón M, C Vargas, A Salinas, A Casanova, L Ibarra, P Berríos. 1996. Prevalencias serológicas para el virus de la diarrea viral bovina y de la rinotraqueítis infecciosa bovina en predios lecheros de la Región Metropolitana de Chile. Av Cs Vet 11, 75-80.

Celedón M, L Palacios, J Pizarro, L Ibarra. 1997ª. Prevalencia de anticuerpos seroneutralizantes para el virus de la diarrea viral bovina en ganado de carne de la Región Metropolitana de Chile. Av Cs Vet 12, 98-100.

Celedón M, L Roco, G Quinteros, M Santibáñez, P Berríos. 1997 Puesta en evidencia del virus diarrea viral bovina en bovinos clínicamente afectados. Arch Med Vet 29, 189-195.

Celedón M, J Carbonell, L Ibarra, J Pizarro. 1998. Detección de bovinos portadores e inmunotolerantes al virus de la diarrea viral bovina en predios lecheros de la Región Metropolitana. Chile. Arch Med Vet 30, 125-132.

Celedón M, A Sandoval, J Droguett, R Calfío, L Ascencio, J Pizarro, C Navarro. 2001. Pesquisa de anticuerpos seroneutralizantes para pestivirus y herpesvirus en ovinos, caprinos y camélidos sudamericanos de Chile. Arch Med Vet 33, 165-172.

Corapi W V, R O Donis, E Dubovi. 1990. Characterization of a panel of monoclonal antibodies and their use in the study of the antigenic diversity of bovine viral diarrhea virus. Am J Vet Res 51, 13881394.

De Calisto, A. 2001. Caracterización genotípica de los aislados nacionales del virus diarrea viral bovina (VDVB) mediante el uso de la reacción en cadena de la polimerasa (PCR). Memoria de titulación, Escuela de Ciencias Veterinarias. Universidad de Chile.

Espejo R, D Escanilla. 1993. Detection of HIV 1 DNA by a simple procedure of polimerase chain reaction using "primer-dimer" formation as a internal control of amplification. Res Virol 144, 243-246.

Evermann JF, ES Berry, TV Baszler. 1993. Diagnostic approaches for the detection of bovine viral diarrhea (BVD) virus and related pestiviruses. $J$ Vet Diagn Invest 5, 265-269. 
Giangaspero M, R Harasawa. 2004. Genetic variety of bovine viral diarrhea virus 2 strains isolated from sheep. J Vet Med Sci 66, 323-326.

Harasawa R, M Giangaspero, G Ibata, PJ Paton. 2000. Giraffe strain of pestivirus: its taxonomic status based on the 5 '-untranslated region. Microbio Immunol 44, 915-921.

Harpin S, S Medí Elahi, E Cornaglia, R H Yolken, Y Elazhary. 1995. The 5' - untranslated region sequence of a potential new genotype of bovine viral diarrhea virus. Arch Virol 140, 1285-1290.

Lee K, J Gillespie. 1957. Propagation of virus diarrhea virus of cattle in tissue culture. Am J Vet Res 18, 952-955.

Loken T. 1995. Ruminant pestivirus infections in animals other than cattle and sheep. Vet Clin North Am Food Anim Pract 11, 597-614.

Mattson DE. 1994. Viral diseases. Update on llamas medicine. Vet Clin North Am Food Anim Pract 10, 345-351.

Meléndez P, MO Celedón. 1995. Pesquisa del virus diarrea viral bovina desde un cuadro respiratorio atípico en novillo. Av Cs Vet 10, 83-85.

Miranda P. 2000. Determinación ultrasonográfica de los períodos de pérdidas embrio-fetales durante la gestación en alpacas (Lama pacos). Memoria de titulación, Escuela de Ciencias Veterinarias. Universidad de Chile.

Müller C. 2003. Aislamiento e identificación de pestivirus y herpesvirus obtenidos de ovinos y caprinos de Chile. Memoria de titulación, Escuela de Ciencias Veterinarias. Universidad de Chile.

OIE. Office International des Épizooties. 2000. Manual of Standards for Diagnostic Tests and Vaccine. Chapter X.5.

Paton DJ, JJ Sands, PM Roehe. 1991. BVD monoclonal antibodies: relationship between viral protein specificity and viral strain specificity. Arch Viro Suppl 3, 47-54.

Paton DJ, JJ Sands, JP Lowings, JE Smith, G Ibata, S Edwards. 1995a. A proposed division of the pestivirus genus using monoclonal antibodies, supported by cross-neutralization assays and genetic sequencing. Vet Res 26, 92-109.
Paton D.J, U Carlsson, JP Lowings, JJ Sands, S Vilcek, S Alenius. $1995^{\text {b }}$. Identification of herd-specific bovine viral diarrhoea virus isolates from infected cattle and sheep. Vet Microbiol 43, 283-294.

Pellerin C, J Van Den Hurk, J Lecomte, P Tussen. 1994. Identification of a new group of bovine viral diarrhea virus strains associated with severe outbreaks and high mortalities. Virology 203, 260-268.

Reinhardt G, S Riedemann, S Ernst, M Aguilar, M Enriquez, J Gallardo. 1990. Seroprevalence of bovine viral diarrhea/mucosal disease in Southern Chile. Prev Vet Med 10, 73-78.

Ridpath JF. 2003. BVDV genotypes and biotypes: practical implications for diagnosis and control. Biologicals 31, 127-131.

Ridpath JF, SR Bolin, EJ Dubovi. 1994. Segregation of bovine viral diarrhea virus into genotypes. Virology 205, 66-74.

Ridpath JF, JD Neill, M Frey, JG Landgraf. 2000. Phylogenetic, antigenic and clinical characterization of type 2 BVDV from North America. Vet Microbiol 77, 145-155.

Vilcek S, S Belák. 1996. Genetic identification of pestivirus strain Frijters as a border disease virus from pigs. J Virol Methods 60, 103-108.

Vilcek S, AJ Herring, PF Nettleton, JP Lowings, DJ Paton. 1994. Pestiviruses isolated from pigs, cattle and sheep can be allocated into at least three genogroups using polymerase chain reaction and restriction endonuclease analysis. Arch Virol 136, 309-323.

Walz PH, JC Baker, TP Mullaney, JB Kaneene, RK Maes. 1999. Comparison of type I and type II bovine viral diarrhoea virus infection in swine. Can J Vet Res 63, 119-123.

Wentz PA, EB Belknap, KV Brock, JK Collins, DG Pugh. 2003. Evaluation of bovine viral diarrhea virus in New World camelids. J Am Vet Med Assoc 223, 223-228.

Xue W, F Blecha, HC Minocha. 1990. Antigenic variations in bovine viral diarrhea viruses detected by monoclonal antibodies. J Clin Microbiol 28, 1688-1693. 